\title{
Attention Deficit Disorder, Residual Type- A Case Study
}

James Stanch, MD

Thomas Jefferson University

Follow this and additional works at: https://jdc.jefferson.edu/jeffjpsychiatry

Part of the Psychiatry Commons

Let us know how access to this document benefits you

\section{Recommended Citation}

Stanch, MD, James (1983) "Attention Deficit Disorder, Residual Type- A Case Study," Jefferson Journal of Psychiatry. Vol. 1 : Iss. 1 , Article 6.

DOI: https://doi.org/10.29046/JJP.001.1.005

Available at: https://jdc.jefferson.edu/jeffjpsychiatry/vol1/iss1/6

This Article is brought to you for free and open access by the Jefferson Digital Commons. The Jefferson Digital Commons is a service of Thomas Jefferson University's Center for Teaching and Learning (CTL). The Commons is a showcase for Jefferson books and journals, peer-reviewed scholarly publications, unique historical collections from the University archives, and teaching tools. The Jefferson Digital Commons allows researchers and interested readers anywhere in the world to learn about and keep up to date with Jefferson scholarship. This article has been accepted for inclusion in Jefferson Journal of Psychiatry by an authorized administrator of the Jefferson Digital Commons. For more information, please contact: JeffersonDigitalCommons@jefferson.edu. 
ATTENTION DEFICIT DISORDER, RESIDUAL TYPE

\section{A CASB STUDY}

James Stanch, M.D.

The syndrome of Minimal Brain Dysfunction (MBD) in children has been well described by a number of authors. Such children were first described in 1941 by Werner and Strauss(1) who made a distinction between brain injury and "simple" mental retardation. In the past such terms as Hyperactive Child Syndrome, Minimal Brain Damage, and Hyperkinetic Behavior Syndrome have been used to describe this syndrome.

MBD in children has been renamed Attention Deficit Disorder (ADD) in DSM-III. This disorder is characterized by developmentally inappropriate inattention and impulsivity. The impulsive shifting of attention is increasingly being recognized as the central deficit in children who previously were classified in terms of their hyperactive behavior.

It has been demonstrated that ADD need not end in childhood, but may continue into adult life(2-18) when it is designated Attention Deficit Disorder-Residual Type (ADD-RT) in DSM-III. The purpose of this paper is to show that ADD-RT is a distinct diagnostic entity, which may exist with and be confused with a variety of other psychiatric syndromes.

Patients with ADD-RT show basic impairment in ability to focus attention. They may have symptom complexes and behavioral patterns that frequently lead to misdiagnosis and consequently ineffective treatment. With the proper medication, remarkable improvement in the presenting symptoms and in the ability to work in therapy may occur, leading to changes in personality structure and behavior.

\section{Case Report}

A 29 year old divorced, unemployed white male living with his parents, came to the emergency room. He complained of "talking too much," an inability to stop drinking, anxiety and chronic difficulties in interpersonal relationships.

The history was gleaned from hospital records, family members and the patient. It is rather lengthy and will be presented in terms of salient positive findings.

The patient has had life long problems with difficulty completing tasks and impulsivity. As a child he was described as being hyperactive, clumsy and impulsive. He was evaluated at the Childrens Hospital of Philadelphia, and was diagnosed as having Minimal Brain Dysfunction. His problems continued, despite counselling at school and he eventually dropped out in ninth grade despite a high IQ. He has continued to do poorly in society, not being able to hold a job or establish a long-term relationship.

Dr. Stanch is a first year psychiatry resident. 
He became heavily involved in drug abuse, and through this as well as his erratic behavior, entered the psychiatric care system in his late teens. He has been hospitalized repeatedly, diagnosed variously as having Bipolar Disorder-Manic phase, Paranoid Schizophrenia, numerous Personality Disorders, and Substance Abuse. Physical examination never showed any abnormalities and EEG and CAT scans have been normal. He failed to respond on three trials of Lithium, treatment with antipsychotics including Haldol, Thorazine, Prolixin, Loxitane, stelazine, Navane, minor tranquilizers, and methadone. The patient did show a short-lived moderate improvement to ECT in a prior hospitalization. The course of his previous psychiatric hospitalizations is well summarized by a remark from a 1981 discharge summary: "It was very difficult to keep him in the group therapies, because he would, ump out in the middle and behave inappropriately. This was all part of the picture of his hypomania which was unresponsive to antipsychotic medication as well as Lithium. Most that could be done for him was to give him so much medication that he would sleep; however, after waking, the patient would behave in exactly the same manner."

\section{Family History}

The patient has a son diagnosed as having Attention Deficit Disorder, who is being treated with methylphenidate (Ritalin). The patient's father and brother have been treated for alcoholism.

\section{Mental Status Exam}

The patient presented as a short, swarthy, youthful-appearing white male patient with normal gait and coordination dressed in hospital clothes, with poor personal hygiene. He shook hands in an engaging fashion, was extremely fidgety (constantly moving his hands and feet) and markedly anxious. He displayed tense posture. He smiled frequently and jumped quickly from one subject to another. His speech was rapid and had a pressured quality. His affect had fair range and was mood congruent (at times somewhat euphoric). His manner was generally pleasant and cooperative. He seemed to be quite disorganized in his thinking with marked distractability and poor concentration; his attention was wandering. He could stay on one thought for only a few minutes and then moved on to something else. Indicators of psychotic thinking (e.g., circumstantiality, ideas of reference, delusions, loose associations, auditory-visual hallucinations, etc.) were not present. The patient was oriented to time, place and person. Memory was intact. General information showed poor fund of knowledge. The patient interpreted proverbs adequately, but had poor judgement and limited insight.

\section{Hospital Course}

After being admitted to a closed psychiatric unit, he was started on pemoline (Cylert), a non-amphetamine central nervous system stimulant. The initial dose was started at $37.5 \mathrm{mg}$ once daily and was gradually titrated (by increments of $18.75 \mathrm{mg}$ every three days) up to $75 \mathrm{mg} \mathrm{p.o.} \mathrm{in} \mathrm{one} \mathrm{morning}$ dose. After the first dose, a positive response was noted. He became less intrusive with decrease in motor activity, talkativeness, and a slowing of 
"racing thoughts." For the first time in many hospitalizations he was able to contribute to and benefit from the milieu. A gradual improvement was noted by staff, patient and family members during his three week hospitalization and has continued for several months while attending partial hospital.

\section{Discussion}

ADD-RT can be diagnosed according to two schemes:

DSM-III Criteria - Attention Deficit Disorder, Residual Type:

A. The individual once met the criteria for Attention Deficit Disorder with Hyperactivity. This information may come from the individual or from others, such as family members.

B. Signs of hyperactivity are no longer present, but other signs of the illness have persisted to the present without periods of remission, as evidenced by signs of both attentional deficits and impulsivity le.g., difficulty organizing work and completing tasks, difficulty concentrating, being easily distracted, making sudden decisions without thought of the consequences).

c. The symptoms of inattention and impulsivity result in some impairment social or occupational functioning.

D. Not due to Schizophrenia, Affective Disorder, Severe or Profound Mental Retardation, or Schizotypal or Borderline Personality Disorders.

Utah Criteria $(1,2,3,4)$ :

A. Motor hyperactivity persisting from childhood

B. Attentional deficits persisting from childhood

C. Affective lability

D. Inability to complete tasks

E. Hot or explosive temper

F. Impaired interpersonal relationships over time

G. Impulsivity

H. Stress intolerance

Exclusion criteria: The subject never met DSM-III criteria for schizophrenia, schizoaffective disorder, primary affective disorder, schizotypal personality, or profound mental retardation or borderline personality disorders. 
In this case we were concerned that the patient failed by the exclusion criteria, since he had a diagnosis of primary affective disorder in the past. This was weighed against the following:

1. History of $\mathrm{ADD}$ as a child that appeared to continue into adulthood.

2. Positive family history; (a) patient's son is a "hyperactive child" treated presently with methylphenidate. (b) The patient's father and brother have a history of alcohol abuse which has been associated with ADD-RT(21, $25,26)$.

3. The patient gave a seemingly paradoxical history of being able to "relax, cope and keep my mouth shut" when abusing amphetamines $(29,30)$.

4. Extensive history of treatment failure.

After much discussion and consideration, it was felt that a trial of a stimulant was indicated. Past studies of ADD-RT have demonstrated that stimulant medication produces significant improvement in adults(19-22). Pemoline was chosen because it has been shown to have less abuse potential(27). Its longer action makes possible a one time daily dose(28).

It has been theorized that patients with ADD not only have impairment in focusing attention on the exterior world, e.g., reading, but also have difficulties in focusing on the "internal world" of feelings and thoughts, e.g., experiencing subtle emotional states. From this primary deficit a number of secondary psychological and behavioral abnormalities occur.

This case serves to demonstrate that ADD-RT may present as "hypomania" that does not respond to classical treatment. It also shows the importance of careful history taking. Medication can produce a quick change in capacity to focus attention and concentration, yielding symptomatic relief and helping the patient to use psychotherapy to begin to alter characterologic problems. 


\section{REFERENCES}

1. Werner H, Strauss: Abnormal Social Psychology $36: 236-248,1941$.

2. Arnold EL, Strobl D, Weisenbrug $A$ : The hyperkinetic adult. JAMA $222: 693-694,1972$.

3. Morrison JR, Minkoff $K$ : Explosive personality as a sequal to the hyperactive child syndrome. Compr Psychiatry 16:343-348, 1975.

4. Shelly EM, Reister FD: Syndrome of MBD in young adults. Dis Nerv Syst $33: 335-339,1972$.

5. Mendelson W, Johnson N, Stewart MA: Hyperactive children as adolescents: a follow-up study. J Nerv Ment Dis 153:273-279, 1971.

6. Huessy HR, Metoyer M, Townsend M: Eight to ten year follow-up of 84 children treated for behavioral disturbances in rural Vermont, Acta Paedopsychiatrica 40:230-235, 1974 .

7. Weiss G, Hechtman L, Perlman T, et al: Hyperactives as young adults: A controlled prospective ten year follow-up of 75 children. Arch Gen Psychiatry 36:675-681, 1979.

8. Hammar SL: School underachievement in the adolescent: A review of 75 cases. Pediatrics 40:373-381, 1967.

9. Ackerman PT, Dykman RA, Peters JE: Teenage status of hyperactive and nonhyperactive learning-disabled boys. Am J Orthopsychiatry 47:577-596, 1977.

10. Hechtman MD, Weiss G, Finklestein F, et al: Hyperactives as young adults: Preliminary report. Can Med J 115:625-630, 1976.

11. Safer DJ, Allen RP: Stimulant drug treatment of hyperactive adolescents. Dis Nerv Syst 36:454-457, 1975.

12. MacKay MC, Beck L, Taylor R: Methylphenidate for adolescents with minimal brain dysfunction. NY Stat $\geq$ J Med 73:551-554, 1973.

13. Borland BL, Heckman HK: Hyperactive boys and their brothers: a 25-year follow-up study. Arch Gen Psychiatry 33:669-675, 1976.

14. Morris нH, Escoll PJ, Wexler R: Aggressive behaviors of childhood: a follow-up study. Am J Psychiatry 112:991-997, 1956.

15. O'Neal P, Robins LM: The relation of childhood behavior problems to adult psychiatric status: a 30 year follow-up study of 150 patients. Am J Psychiatry 114:961-969, 1958. 
16. Menkes MH, Rowe JS, Menkes JH: A 25-year follow-up study on the hyperkinetic child with MBD. Pediatrics 39:393-399, 1967.

17. Hartocollis P: The syndrome of minimal brain dysfunction in young adult patients. Bull Menninger Clin 32:102-114, 1968.

18. Quitkin F, Klein DF: Two behavioral syndromes in young adults related to possible minimal brain dysfunction. J Psychiatr Res 7:131-142, 1969.

19. Wood DR, Reimherr FW, Wender PH, et al: Diagnosis and treatment of minimal brain dysfunction in adults. Arch Gen Psychiatry 33:1453-1460, 1976.

20. Wender PH, Reimher FW, Wood DR: Attention deficit disorder ("minimal brain dysfunction") in adults: a replication study of diagnosis and drug treatment. Arch Gen Psychiatry 38:449-456, 1981.

21. Wender PH, Reimherr FW, Wood DR: The prevelance of attention deficit disorder, residual type, or minimal brain dysfunction, in a population of male alcoholic patients. Psychiatry 140:1, January 1983.

22. Mann HB, Greenspan SI: The identification and treatment of adult brain dysfunction. Psychiatry 133:9, September 1976.

23. Morrison JR, Steward MA: A family study of the hyperactive child syndrome. Biol Psychiatry 3:189-195, 1971.

24. Cantwell DP: Psychiatric illness in the families of hyperactive children. Arch Gen Psychiatry 27:414-417, 1972.

25. Arkonac 0, Guze SB: A family study of hysteria. N Engl J Med 268:239-242, 1963.

26. Tarter RE, McBride H, Buonpane $\mathrm{N}$, et al: Differentiation of alcoholics: childhood history of minimal brain dysfunction, family history and drinking pattern. Arch Gen Psychiatry 34:761-768, 1977.

27. Dren AT, et al: Comparison of pemoline, cocaine, methamphetamines and methylphenidate self-administration in monkeys. Pharmacology $13: 381$, 1971.

28. Physicians Desk Reference - P.D.R. edition 37:510, 1983.

29. Tecce JJ, Cole JO: Amphetamine effects in man: paradosical drowsiness and lowered electrical brain activity (CNV), Science 185:451-510, 1974.

30. Rapport JL, Buchsbam MS, Zahn TP, et al: Dextroamphetamine: cognitive and behavioral effects in normal prepubertal boys. Science 199-560-563, 1978.

31. Williams JBW: Diagnostic criteria for attention deficit disorder, residual type. Diagnostic and Statistical Manual of Mental Disorders, (DSM-III), third edition, 44-45, 1980 . 